\title{
HOW DOES “SUBJECTIVE I” INFLUENCE A QUALITATIVE RESEARCH QUESTION, THEORETICAL APPROACH AND METHODOLOGIES?
}

MICHAEL EBE KALU

(Received 10 September 2018; Revision Accepted 12 November 2018)

\section{ABSTRACT}

The "subjective Is" are those values and beliefs that a researcher or a practitioner brings to a research project or practice. The "subjective I" enables the researchers or practitioners to ask three sets of questions (a) "who am I?"; (b) what factors influenced or informed the beliefs and values; and (c) how these beliefs and values affected my approach to developing a research interest, its research questions, theoretical approach, and methodologies. While these questions may not have an explicit influence on quantitative inquiries, it is the bedrock for a qualitative inquiry. Therefore, it is very important that qualitative researchers should engage in the process of identifying their "Subjective l's" and reflect on how these could influence their preferred research interest, its research questions, theoretical approach and methodologies. This paper has three sections. First, I provided a description of reflexivity, highlighting its purpose in a qualitative research building on evidence from the literature. Subsequently, I provided the strengths of being reflexive as well as identify the potential limitations of not being reflexive in qualitative inquiry. Second, I identified and described three of my "subjective l" as inspired by Pushkin (1998). Third, I discussed how the identified three "subjective I" would influence some components of a hypothetical research topic including its theoretical approach, the research questions, and methodology approach.

KEYWORDS: Reflexivity, Qualitative Injury, Subjective I

\section{"WHO AM I?"}

Literally, I have not explicitly asked myself this questionwho am I?... but really who am I? This is a question that requires a subjective evaluation of (a) one's life styles, beliefs, and values; and (b) what factors that influences or informed these lifestyles, beliefs and values. It is quite a shame that I have never stepped back to ponder on who am I? let alone clearly writing it down. However, this reflexive article would provide me the opportunity to cultivate the habit of being reflexive in my practice as a physiotherapist and a researcher.

\section{WHAT IS REFLEXIVITY?}

In an effort to understand reflexivity, I conducted a quick search on database-PsycINFO using "reflexivity" as a search term. The search yielded 2783 results, and majority of the authors in these articles interchangeably used reflectivity and reflexivity. On further reviewing the literature, there was an explicit distinction of the two terms. Reflection is a state of mind that supports thoughtful questions about something you want to understand (Hibbert, Coupland and Maclntosh, 2010).Reflexivity is a conscious process of unmasking hidden conflicts and assumptions/ideas/beliefs with a goal of emancipating thinking and action of self, others, reality and context (Holmes, Cockburn-Wooten, Motion, Zorn and Roper, 2005; Hibbert, 2013).
Typically, to be reflective requires a thoughtful question about self, whereas reflexivity is a thoughtful question about yourself and others (Finlay, 2002). Another perspective to understanding the difference is that in reflection, the person reflecting achieve "some" learning but the person often remains the same whereas in reflexivity, the person achieves learning and the person also changed (Mauthner and Doucet, 2003; Hibbert, Sillince, Diefenbach and Cunliffe, 2014). Therefore, reflexivity is developed through a process of critical reflection of self-realisation and others.

Interestingly, Pillow (2010) in her article critically explore what she calls "the four common trends in the presentday reflexivity": reflexivity of self, reflexivity of others, reflexivity of truth and reflexivity as a transcendence. While the first three common trends seem clear, the reflexivity as a transcendence could be interpreted to the notion of using reflexivity as the main or supreme tool in a qualitative study (Hall and Callery, 2001; Cutcliffe, 2003; Pillow, 2003). Generally, reflexivity is complete when the process involving self-analysis of subjective assumptions is recursive, such that it creates room for us to accept opposing opinions we held about that phenomena (Carson \& Fisher, 2006; Sword, 1999; Adams, 2003).Additionally, I believe the most effective reflexive process is one that often challenges the patterns of our foundational assumption as a researcher. Simply put, being reflexive entails a deliberate awareness of differences in people's perceptions, ideas

Michael Ebe Kalu, School of Rehabilitation Science, McMaster University, Hamilton, ON Canada 
and assumptions from our own assumptions with an aim of creating a well-rounded opinion or interpretation of a phenomenon. This deliberate awareness can be expressed by the researcher recognising the influence of context (cultural and physical) of others and self so that it is not a threat to the acquiring and interpretation of knowledge about phenomena. While reflexivity is important, its excessive use in qualitative inquiry hinders the interpretation process that characterised the subjective value of the qualitative evidence.

\section{THE PURPOSE OF REFLEXIVITY IN QUALITATIVE RESEARCH}

Most qualitative research approach is conceptualised as a subjective process and do not permit objectivity and control as in quantitative research. Historically, a typical quantitative methodologist believes that qualitative research is less of a scientific inquiry to quantitative research. To provide reasons that qualitative inquiry is a peculiar form of researches, qualitative methodologist develops approaches such as reflexivity to serve as a strategy of checking rigour and trustworthiness of qualitative findings. Typically, reflexivity during qualitative research is seen as methodological power that qualitative researchers can use to question the realities in research practices (Pillow, 2010). Reflexivity is often considered as a major strategy for quality check in a qualitative study (Berger, 2015; Bradbury-Jones, 2007; Ahmed Dunya, Lewando and Blackburn, 2011), and serves as a measure of determining more "accurate" or more "valid" research findings (Lewis, 2015;Malteurd, 2001). However, I am disturbed how experienced qualitative researchers seems to be laying more emphasis on the role of reflexivity as a measure to depict more "valid" and more "accurate" findings, rather than focusing on encouraging young researcher to understand and cultivate the habit of reflexivity at the early stage of their career as a qualitative researcher. Qualitative research findings are subjective and most time, context dependent, in terms of applicability, therefore the issue of more "valid" and "accurate" findings should not be of paramount importance in qualitative research.

Moreover, the use of reflexivity has increased the awareness of researcher subjectivity in the research process (Watt, 2007). Are searcher being aware of self, others and context does necessarily entail complete delineation of the researcher's perspective (bracketing) as explained in the classical criteria for rigour confirmability-(Poduthase, 2015; Lincoln and Guba, 1985).However, the increase awareness of the researcher subject ivityallows a researcher to become aware of what him/her sees, what inhibit his/her seeking of knowledge, and how does "who am I?, who have I been?, who do I think I am?" could influence the method and/or process of a particular inquiry (Berger, 2015; Pillow, 2010).

Interestingly, being reflexive help the researcher to deconstruct his/her authority and power in the research process (Arvay, 2003); therefore, allowing for opendialogic discussion with individuals of whom their perspective, value and beliefs may disturb the researcher own beliefs and values. This creates a synergy for the researcher to conduct a research "with" and not "on" the participants and/or context (Russel and Kely, 2002). Furthermore, reflexivity allows a process of creating a knowledge that recognises the intersection of the researchers own perceptions, others' perceptions and how the context influences these perceptions. Arguably, the essence of reflexivity accounts for ethics assuring that the researcher clearly creates a knowledge that is trustworthy, reflects and obeys the ideas and right of the individuals interviewed (Guillemin and Gilliam, 2004;Cloke, Cooke, Cursons, Milborune and Widdowfield 2000).

\section{STRENGTHS OF BEING REFLEXIVE AND LIMITATIONS OF NOT BEING REFLEXIVE}

Being reflexive creates a platform for a well-rounded decision and interpretation of phenomena being studied. This is because reflexivity changes the assumptions, ideologies, social and cultural beliefs and questions subjective behaviours that would perhaps subdue the voices of others. The researcher maintains being reflexive by critically and consciously making efforts to narrate how subjective factors such as race, sexual orientation, sex, experiences influences all stages of research (Pillow, 2010; Mauther and Doucet, 2003;Gemignani, 2011; Kosygina, 2005). Therefore, this process helps to provide insight into how "realities" and knowledge of a particular phenomenon are produced. I could argue that through a multiple filtering of the factors listed above, a well-rounded knowledge about phenomena is created. Reflexivity also highlights the importance of a researcher critically becoming consciously aware of his/her role and its implication throughout the research process.

Additionally, since reflexivity is a continuous habit a qualitative researcher should have throughout the research process (Bradbury-Jones, 2007). I agree with Watt (2007) statement that being reflexive is a subjective process of continuously becoming a better qualitative researcher. This subjective process can be achieved through an iterative approach of the researcher returning to their research journal to explore deeper the concepts under study (Ben-ari \& Enosh, 2010; Watt, 2007; Gentles, Jack, Nicolas and Mckibbon, 2014; Berger, 2015; Ellis \& Bonchner, 2000; Groove, 2017). Referring back to reflexive research journals often help identify missed biases, feelings and thoughts that most researchers often didn't understand at the first level of reflexivity; and this provides an opportunity for more in-depth understanding and interpretation of a phenomenon.

Reflexivity allows an early qualitative researcher to understand all other aspect of qualitative research methodology (Watt, 2007), because being reflexive encourages the researcher to understand the fundamental philosophy of qualitative subjectivity. This understanding sets a foundation for recognising and further understanding of other aspect of qualitative research. This is one of the hidden strengths of reflexivity that even some teachers of qualitative inquiry courses have not been able to explore fully. For instance, assuming I was exposed to reflexivity in my first qualitative class, it would have been easier for me to understand other aspect of qualitative research. 
Russell and Kelly (2002) stated that good research questions often spring from the researcher passion, values and experiences; however, I would argue that better research questions spring from a prolong acts of reflexivity between yourself, co-researchers, participants and the context of which the phenomenon is studied. Therefore, early reflexive actions create stronger and pragmatic research questions especially as an educational researcher. Additionally, reflexivity plays a vital role in shaping the researcher's data collection process, analysis, interpretation and writing of the findings; because explicit understanding emerges as the researcher's analyses his/her own experience in the field (Ellis \& Bochner, 2000; Shaw, 2010). Reflexivity does notonly serve as a checkmate during analysis and interpretation of research findings butcould also serve as a source of triangulation in qualitative research (Bradbury-Jones, 2007).

\section{LIMITATIONS OF NOT INTEGRATING REFLEXIVITY INTO A QUALITATIVE RESEARCH PROJECT.}

Not being reflexive during qualitative research project places a doubt on the quality and interpretation of a knowledge created in a qualitative research. It also creates an imbalance status in the researcherresearched relationship, which favours the researcher and subdues the voice of the researched (Bishop \& Shepherd, 2011). When the voice of the researched is subdued, it cast a doubt on the interpretation of the knowledge created; which often translate to poor quality of the research findings. This ultimately affects the adaptability and applicability of the research findings in a similar context (D'Cruz, Gilingham and Melendez, 2007). Furthermore, not being reflexive as a researcher creates a doubt on the research process, thereby delimiting transparency and accountability of the findings (Lietz, Langer \& Furman, 2006). It also violates the principles of ethics which advocate a fair and clear interpretation of research findings to enhance applicability in the knowledge translation principles (Bishop \& Shepherd, 2011; Smith, 1999).

\section{MY "SUBJECTIVE I"}

In this section, I will describe three of my "subjective I" and subsequently in the preceding section describe how these three "subjective Is" have affected my research interest, question and approach.

The multicultural I- This "subjective I" explains the biases I have accumulated over time after living in several regions of the world including Africa, Europe and North America. I have generated multiple biases, which are reflected as the habit of comparing events, activities, clinical practices, people's values, cultures and beliefs. This has constantly placed me in a position of resonating more with individuals or ideas that encompass multiculturality. An increasing awareness of this "subjective I" would allow me to appreciate, understand and interpret experience of people with single cultural identity.

The Holistic I- linking with the multicultural I, I often believe that every problem or issue should be addressed holistically to grasp the full understanding of the phenomena being studied. While this may sound true, it is possible that I often value opinions or events that gives a holistic information, thereby ignoring opinions that discusses an aspect of the problem. This becomes a problem because this "subjective I" will always resonate with opinions that I deemed holistic.

The profession-advocates I- This is the "subjective I" that always tries to portray the physiotherapy profession as It is likely that I would resonate more with a physiotherapist that has the same passion of promoting the profession; therefore, it is possible that I would be bias towards any of my participants that I presume that their idea doesn't speak well of the physiotherapy profession. This would be evident in every aspect of my research stating from drafting the research question, recruitment, data collection, analysis, interpretation and writing.

\section{HOW DOES MY “SUBJECTIVE 1” AFFECTS;}

(a) My research interest- I am interested in developing a mobility enhancement comprehensive care model for older adult across care transitions. The profession-advocates I would be interested in exploring processes of enhancing mobility specifically looking out to those processes that portrays good image of the physiotherapy profession in the eyes of the public. The holisticl will focus on a "comprehensive" approach that has been pre-determined by me, therefore it is possible that comprehensive approach would also focus on portraying a good image of the physiotherapy profession. Realising and explicitly journaling on this "subjective I" at the early stage of my research would provide a platform for reflexivity.

(b) My theoretical approach to research. $-\mathrm{I}$ am interested in using social constructivism lens (Creswell and Poth, 2018) to understand how physiotherapists enhance mobility for older adults from inpatient geriatric rehabilitation unit to community. My multicultural I may start favouring those that have diverse opinion maybe because of their exposure to different culture, thereby not focusing more on the influence of the single-context as a process of creating the knowledge.

(c) Research question- How does physical therapists engage in enhancing mobility for older adults during care transition from inpatient rehabilitation to community?

My profession advocates I would be interested in the processes that promotes mobility as a physical form of exercise (which is a typical physiotherapy promotion program); and my holistic I would probably at the same time ignore any evidence that didn't sound holistic to me, thereby introducing bias and one sidedness to my research.

(d) My approach is interpretive description, that aimed at generating knowledge that would improve clinical understanding of a healthcare challenge based on the theoretical paradigm of a specific discipline (Thorne, 2016). Therefore, relating to my research question, I hope to generate knowledge that would enhance mobility for older adults from inpatient rehabilitation unit to community. I assume that the multicultural I will likely favour recruitment of physiotherapists that practice in a multicultural area since I would likely influence my recruitment strategy, and influence my interview process (Jack, 2008). The 
professional advocate I have a potential negative influence during the interview process, whereby I would be probing to get that information that portrays well of the profession. Acknowledging this and thinking on how this would influence my study is crucial.

\section{CONCLUSION}

Reflexivity is a great strategy to enhancing rigour in qualitative research process. I kept a reflexive journal explaining how writing this article evolved over time. In this article, I started on a personal reflection (selfinquiry) on the difference between reflection and reflexivity. Subsequently, I was able to provide a clear definition that captures my understanding of reflexivity. I clearly identified my Subjective I: multicultural I, Holistic I and profession-advocate I and subsequently highlighted how these "subjective Is" would affect and influence my research interest, its philosophical assumptions, research approach and research questions.

\section{REFERENCES}

Adams, M. 2003. The reflexive self and culture: a critique. British Journal of Sociology, 54, 221238. doi:10.1080/0007131032000080212.

Ahmed Dunya, A. A., Lewando, H.G., and Blackburn, C. 2011. Issues of gender, reflexivity and positionality in the field of disability: researching visual impairment in an Arab society. Qualitative Social Work 10(4), 467-484. doi.org/10.1177/1473325010370188.

Arvay, M. 2003. Doing reflexivity: A collaborative, narrative approach. In L. Finlay and B. Gough (Eds.), Reflexivity pp.163-175. The United Kingdom, Oxford: Blackwell.

Ben-Ari, A., and Enosh, G. 2010. Process of Reflectivity Knowledge construction in Qualitative Research. Qualitative Social Work, 10(2), 152171. DOI: $10.1177 / 1473325010369024$

Berger, R. 2015. Now I see it, now I don't: researcher's position and reflexivity in qualitative research. Qualitative Research, 15(2), 219-234. doi.org/10.1177/1468794112468475

Bishop, E. C., and Shepherd M.L. 2011. Ethical reflections: Examining reflexivity through the Narrative Paradigm. Qualitative Health Research, 12(9), 1283-1294. doi.org/10.1177/1049732311405800

Bradbury-Jones, C. 2007. Enhancing rigor in qualitative health research: exploring subjectivity through Peshkin's l's. Journal of Advanced Nursing 59, 290-298. 10.1111/j.1365-2648.2007.04306.

Carson, L., and Fisher, K. 2006. Raising the bar on critically: Students' critical reflection in an internship program. Journal of Management Education, 30(5): 700-723. doi.org/10.1177/1052562905284962
Cloke, P., Cooke, P., Cursons, J., Milborune, P., and Widdow field, R. 2000. Ethics, reflexivity and research: encounters with homeless people. Ethics, Place and Environment,3, 133154.doi.org/10.1080/713665889

Creswell, J. W. and Poth, C. N. 2018. Qualitative inquiry and research design: Choosing among five approaches $\left(4^{\text {th }}\right.$ ed.). Thousand Oaks, CA: Sage publications.

Cutcliffe, J. R. 2003. Reconsidering reflexivity: Introducing the case for intellectual entrepreneurship. Qualitative Health Research, 13(1),136-148. doi:10.1177/1049732302239416

D' Cruz, H., Gillingham, P., and Melendez, S.2007. Reflexivity, its meaning and relevance for social work: a critical review of the literature. British Journal of Social Work,37(1), 73-90. doi.org/10.1093/bjsw/bcl001

Ellis, C., and Bochner, A. P. 2000. Autoethnography, Subjective narrative, reflexivity: Researcher as subject. In N. K. Denzin and Y. S. Lincoln (Eds.), Handbook of qualitative research (2nd ed., pp. 733-768).

Thousand Oaks, CA: Sage.

Finlay, L. 2002. "Outing" the researcher: The provenance, process, and practice of reflexivity. Qualitative Health Research, 12(4), 531-545.

Gemignani, M. 2011. Between researcher and researched: an introduction to counter transference in qualitative inquiry. Qualitative Inquiry, 17(8), 701-708. doi.org/10.1177/1077800411415501

Gentles, S.J., Jack, S.M., Nicholas, D.B., and McKibbon K.A. 2014. Critical approach to reflexivity in Grounded theory. The Qualitative Report, 19(44),1-14. Retrieved from http://nsuworks.nova.edu/tqr/vol19/iss44/3

Grove, J. 2017. Researching a marginalized group: Reflections on being an outsider. Counseling and Psychotherapy Research, 17, 176-180. doi:10.1002/capr.12120

Guillemin, M., and Gillam, L. 2004. Ethics, reflexivity and 'ethically important moments' in research. Qualitative Inquiry, 10(2), 261-280. doi.org/10.1177/1077800403262360

Hall, W. A., and Callery, P. 2001. Enhancing the rigor of grounded theory: Incorporating reflexivity and relationality. Qualitative Health Research, 11(2), 257-272. doi.org/10.1177/104973201129119082

Hibbert, P. 2013. Approaching reflexivity through critical reflection: issues for critical management education. Journal of Management Education, 37(6),803-827. doi.org/10.1177/1052562912467757 
Hibbert, P., Coupland, C. and Maclntosh, R. 2010. Reflexivity: recursion and relationality in organizational research processes. Qualitative Research in Organizations and Management: An International Journal, 5(1),47-62. doi.org/10.1108/17465641011042026

Hibbert, P., Sillince, J., Diefenbach, T. and Cunliffe, A. 2014. Relationally Reflexive Practice: A Generative Approach to Theory Development in Qualitative Research. Organizational Research Methods, 17(3), 278- 298. doi.org/10.1177/1094428114524829

Holmes, P., Cockburn-Wooten, C., Motion, J., Zorn, T. and Roper, J. 2005. Critical reflexive practice in teaching management communication. Business Communication Quarterly, 68(2), 247256. DOI: $10.1177 / 1080569905276668$.

Jack, S. 2008. Guidelines to Support NurseResearchers Reflect on Role Conflict in Qualitative Interviewing. Open Nursing Journal, 2, 58-62. doi: $10.2174 / 1874434600802010058$

Kosygina, L.V. 2005. Doing gender in research: reflection on experience in field. Qualitative Report, 10(1), 87-95. Retrieved from http://nsuworks.nova.edu/tqr/vol10/iss $1 / 5$

Lewis, S. 2015. Qualitative inquiry and research design: Choosing among five approaches. Health Promotion Practice, 16(4), 473-475. doi.org/10.1177/1524839915580941

Lietz, C. A., Langer, C.L., and Furman, R. 2006. Establishing trustworthiness in qualitative research in social work: implications from a study regarding spirituality. Qualitative Social Work, 5(4), $441-458$. doi.org/10.1177/1473325006070288

Lincoln, Y. S., and Guba, E. G. 1985. Naturalistic inquiry. Beverly Hills, CA: Sage.

Malterud, K. 2001. Qualitative research: standards, challenges, and guidelines. Lancet, 258:483488. doi.org/10.1016/S0140-6736 (01)05627-6

Mauther, N. S., and Doucet, A. 2003. Reflexive accounts and accounts of reflexivity in qualitative data analysis. Sociology 37(3), 413431. doi.org/10.1177/00380385030373002

Peshkin, A. 1988. In search of subjectivity-one's own. Educational Researcher, 1797), 17-21.

Pillow, W. 2003. Confession, catharsis, or cure? Rethinking the uses of reflexivity as a methodological power in qualitative research. International Journal of Qualitative Studies in Education, $\quad 16(2)$, 175-196. doi.org/10.1080/0951839032000060635

Poduthase H, 2015. Rigor in qualitative research:

Promoting quality in Social Science Research. Research Journal of Recent Science, 4, 25-28. Retrieved from www.isca.in, www.isca.me

Russel, G. M., and Kely, N. H. 2002. Research As interacting dialogic process: implications for reflexivity. Forum: Qualitative Social Research, 3(2), 18. Retrieved from http://www.qualitativeresearch.net/index.php/fqs/article/view/831/1807

Shaw, R. 2010. Embedding reflexivity within experiential qualitative psychology. Qualitative Research in Psychology, 7(3) 233-243. doi.org/10.1080/14780880802699092

Smith B.A. 1999 Ethical and methodological benefits of using a reflexive journal in hermeneuticphenomenological research. Journal of Nursing Scholarship,31(4),359-363.

DOI: $10.1111 /$ j.1547-5069.1999.tb00520.x

Sword, W. 1999.Accounting for presence of self: Reflection on doing qualitative research. Qualitative Health Research, 9(2), 270-278. doi.org/10.1177/104973299129121839

Thorne, S. 2016.Interpretive description: Qualitative research for applied practice $\left(2^{\text {nd }}\right.$ ed.). NY: Routledge.

Watt, D. 2007 . On becoming a qualitative researcher: the value of reflexivity. The Qualitative Report, 12 (1), 82-10. Retrieved from http://www.nova.edu/ssss/QR/QR12-1/watt.pdf 